\title{
Efeito barreira em cidades médias brasileiras: o caso de viagens não motorizadas em São Carlos, SP
}

\author{
Community severance in Brazilian medium-sized cities: \\ the case of non-motorised journeys in São Carlos, SP
}

\author{
Mylena Cristine Rodrigues de Jesus \\ Daniela Vanessa Rodriguez Lara \\ Antônio Nélson Rodrigues da Silva
}

\section{Resumo}

${ }^{1}$ Mylena Cristine Rodrigues de

'Universidade de São Carlos - SP - Brasil

2Daniela Vanessa Rodriguez Lara ¿Universidade de São Paulo São Carlos - SP - Brasil

${ }^{3}$ Antônio Nélson Rodrigues da

Silva

3Universidade de São Paulo São Carlos - SP - Brasil

Recebido em 28/07/20 Aceito em 18/01/21 istemas de transporte visam melhorar as condições de mobilidade. Podem, no entanto, provocar efeitos negativos sobre os deslocamentos, como é o caso do efeito barreira. O objetivo deste estudo é avaliar se uma via urbana se constitui em uma barreira para deslocamentos a pé, bem como identificar variáveis que alteram a percepção dos pedestres sobre esse efeito. A via estudada, localizada em uma cidade média (São Carlos, SP), apresenta intenso tráfego motorizado. Um questionário foi utilizado para identificar características pessoais (idade, renda, etc.) e padrões de viagens e mobilidade (dificuldades de caminhar, percepções sobre o tráfego, etc.). Os dados de 103 respondentes foram examinados com o teste Qui-quadrado de independência, em busca de evidências de associações entre as dificuldades enfrentadas pelos entrevistados ao andar a pé e suas características individuais e percepções do efeito barreira. No caso da percepção do efeito barreira devido à velocidade e ao volume de tráfego, há evidências de associação entre os trechos que exigem esforço físico excessivo, ruas muito largas e poluição sonora ou do ar. Assim, a via analisada representa, em alguns aspectos, uma barreira aos deslocamentos a pé.

Palavras-chave: Efeito barreira. Separação da comunidade. Pedestres. Infraestrutura de transporte. Modos não motorizados.

\section{Abstract}

Transport systems are designed to improve mobility conditions. Nonetheless, they can also have negative impacts on displacements, such as the barrier effect. The aim of this study is to evaluate whether or not an urban street acts as a barrier to walking trips and to identify variables that change the perception of pedestrians about this effect. The road studied, located in a medium-sized city (São Carlos, SP), has intense motorized traffic. A questionnaire was designed to register personal characteristics (age, income, etc.) as well as mobility patterns (difficulties in walking, perceptions about traffic, etc.). Data from 103 respondents were examined using the Chi-squared test of independence to look for evidence of associations between the difficulties faced by respondents when walking and their individual characteristics and perceptions of community severance. In the case of perception of the barrier effect due to traffic speed and traffic volume, the results showed evidence of an association between stretches that require excessive physical effort, very wide streets and noise or air pollution. Thus, the study indicates that the street analysed constitutes, in some aspects, a barrier to walking trips.

Keywords: Barrier effect. Community severance. Pedestrians. Transport. Infrastruture. Non-motorised mode.

JESUS, M. C. R. de; LARA, D. V. R.; RODRIGUES DA SILVA, A. N. Efeito barreira em cidades médias brasileiras: o caso de viagens não motorizadas em São Carlos, SP. Ambiente Construído, Porto Alegre, v. 21, n. 3, p. 79-95, jul./set. 2021. 


\section{Introdução}

Os sistemas de transporte desempenham um papel fundamental para a sociedade, visto que disponibilizam acesso às diversas oportunidades. Dessa maneira, melhorar o acesso aos sistemas de transporte pode melhorar o bem-estar e a qualidade dos deslocamentos, e diminuir o índice de exclusão social de alguns grupos da sociedade (THOREAU; MACKETT, 2015; VAN SCHALKWYK; MINDELL, 2018; VAN ELDIJK et al., 2020). Em contrapartida, os sistemas de transporte também provocam alguns efeitos negativos para a sociedade, de acordo com Anciaes, Jones e Metcalfe (2018), como congestionamentos, riscos de acidentes, ruído, poluição do ar e da água, e mudanças climáticas, entre outros efeitos que prejudicam o tráfego de pessoas e veículos.

Um desses efeitos, denominado efeito barreira, ocorre quando uma infraestrutura de transporte age como uma barreira aos deslocamentos de pedestres e ciclistas. No caso de ruas e vias urbanas, a velocidade e o volume de tráfego atuam como barreiras que impedem ou dificultam significativamente os deslocamentos locais a pé ou de bicicleta e o acesso a bens e serviços, o que compromete o bem-estar da população (ANCIAES, 2015). Nos últimos anos, alguns estudos têm buscado entender os efeitos das infraestruturas de transporte no cotidiano dos indivíduos (ANCIAES et al., 2016; GUO; BLACK; DUNNE, 2001; LARA; RODRIGUES DA SILVA, 2018, 2019; MINDELL et al., 2017; NIMEGEER et al., 2018; SILVA JUNIOR; FERREIRA, 2008; VAN ELDIJK et al., 2020).

Esse processo é frequente em cidades de maior porte, onde a frota de veículos motorizados é expressiva, sobretudo onde a repartição modal tem forte participação de viagens em veículos motorizados individuais. Isso não é comum, por outro lado, em cidades pequenas, fato que se reflete inclusive em uma carência de referências bibliográficas sobre o assunto. A questão levantada neste estudo, no entanto, diz respeito às cidades que se encontram no meio desse espectro, as chamadas cidades médias. Será possível falar em efeito barreira nesse contexto específico?

Com o propósito de contribuir para uma resposta à questão acima, o principal objetivo deste estudo é identificar se há indícios de que uma via importante de uma cidade média brasileira (ou seja, com população entre 100 e 500 mil habitantes), selecionada por apresentar elevado tráfego de veículos motorizados, atua como barreira aos deslocamentos de pedestres, além de registrar a percepção dos usuários sobre as dificuldades encontradas nos deslocamentos a pé pela região. Para orientar o desenvolvimento do trabalho, foram consideradas algumas questões. É possível afirmar que, em alguns aspectos, a via selecionada atua como uma barreira para a região de estudo? Caso isso se confirme, existem evidências de associação entre as dificuldades enfrentadas pelos pedestres e:

(a) suas características individuais;

(b) suas percepções do efeito barreira devido à velocidade de tráfego; ou

(c) suas percepções do efeito barreira devido ao volume de tráfego.

Para isso, o presente estudo apresenta uma análise exploratória dos dados de entrevistas realizadas com moradores e frequentadores da via selecionada para análise. Os resultados descritos se baseiam essencialmente na percepção dos entrevistados sobre a velocidade e o volume de tráfego na região, e consideram as características individuais dos respondentes e as dificuldades que enfrentam como pedestres. A metodologia é baseada em uma análise descritiva e quantitativa dos dados, com o uso do teste Quiquadrado de independência $\left(\chi^{2}\right)$ para examinar associações entre as variáveis selecionadas.

Essa metodologia permite a compreensão da relevância do efeito barreira a partir das percepções dos entrevistados quanto às vias urbanas de grande tráfego de veículos motorizados. É possível replicar a metodologia deste estudo em outros municípios, em busca de padrões nas percepções dos pedestres quanto ao tráfego de veículos motorizados e de variações do efeito barreira.

A pesquisa contribui também para a identificação das principais causas das dificuldades relacionadas aos deslocamentos a pé na região, bem como para a identificação das características dos entrevistados, de suas interações sociais e de outros fatores que afetam suas viagens e mobilidade. Dessa maneira, a pesquisa traz benefícios indiretos à comunidade local, podendo servir de objeto de apoio à tomada de decisão de políticas públicas urbanas e de transportes direcionadas à construção de um ambiente seguro para os pedestres.

$\mathrm{O}$ artigo foi dividido em cinco seções. A primeira apresenta a introdução ao problema de pesquisa. Na segunda se realiza uma breve revisão da literatura acerca do efeito barreira. Em seguida os procedimentos metodológicos são apresentados, e por fim são indicados os resultados encontrados e as conclusões. 


\section{Revisão da literatura}

Os sistemas de transporte concedem aos indivíduos acesso à diversas oportunidades, como educação, emprego, bens, serviços e lazer. A melhoria do acesso a esses sistemas pode trazer benefícios ao bem-estar e à qualidade dos deslocamentos (THOREAU; MACKETT, 2015; VAN ELDIJK et al., 2020; VAN SCHALKWYK; MINDELL, 2018). Por outro lado, os sistemas de transporte também têm efeitos negativos para a sociedade, como congestionamentos, riscos de acidentes, ruídos, poluição do ar e da água, e mudanças climáticas (ANCIAES; JONES; METCALFE, 2018). Além desses efeitos negativos, os sistemas de transportes podem causar segregação urbana de comunidades. Esse processo, também chamado de efeito barreira, ocorre quando uma infraestrutura de transporte ou altos índices de tráfego motorizado atravessam vizinhanças, interrompendo assim a mobilidade e a acessibilidade dos moradores e frequentadores locais.

O efeito barreira vem sendo estudado pelo menos desde a década de 1960 (ANCIAES, 2015), contudo no Brasil as pesquisas nessa área começaram por volta dos anos 2000. A princípio, o conceito do efeito barreira foi discutido por Appleyard e Lintell (1972) e Soguel (1995) como o efeito do tráfego de veículos motorizados nos deslocamentos dos pedestres e nas interações dos indivíduos. Mais tarde, Guo, Black e Dunne (2001) argumentaram que o efeito barreira também está associado aos problemas causados aos deslocamentos dos pedestres em consequência de barreiras estáticas (vias expressas, em desnível, com existência de taludes elevados, etc.). Posteriormente, Anciaes (2015) e Mindell et al. (2017) acrescentaram que o efeito barreira causa impacto negativo no comportamento, bem-estar e mobilidade dos indivíduos. No Brasil, os primeiros estudos sobre o efeito barreira abordaram o conceito como uma restrição ao movimento de pedestres de um lado para outro de uma via, causada pelo tráfego e pela infraestrutura viária (MOUETTE; AIDAR; WAISMAN, 2000; MOUETTE; WAISMAN, 2004). Posteriormente, o efeito barreira veio a ser tratado como barreiras locais aos deslocamentos realizados por modos não motorizados (LARA; RODRIGUES DA SILVA, 2018; SILVA JUNIOR; FERREIRA, 2008).

Com a transição da definição do conceito do efeito barreira, a compreensão do fenômeno e a busca de meios para medir seus impactos à comunidade evoluíram continuamente. $\mathrm{O}$ estudo desenvolvido por Mindell et al. (2017) apresenta um conjunto de ferramentas para medir o grau do efeito barreira devido às ruas movimentadas e seus impactos. Uma dessas ferramentas consiste na avaliação das condições de saúde, bemestar e mobilidade das pessoas de determinada região por meio de questionários. Com esses recursos, os autores mostram que a proporção de pessoas com o bem-estar prejudicado é maior entre os entrevistados que moram mais próximos à região de estudo. Além disso, a avenida estudada promove segregação urbana da comunidade, que apresenta diferentes níveis de saúde e níveis de status socioeconômico. O ruído e a poluição do ar foram muito citados pelos entrevistados como um impedimento para o deslocamento a pé pela região (MINDELL et al., 2017). Adicionalmente, van Eldijk et al. (2020) propõem quatro indicadores de acessibilidade local - tempo de viagem, opções de destino, área de influência e eficiência dos serviços públicos (ambulâncias, transporte público, coleta de lixo, etc.) - para mensurar os impactos locais do efeito barreira provocado por infraestruturas de transportes.

No tocante às consequências associadas ao efeito barreira, o estudo realizado por Silva Junior e Ferreira (2008), em Uberlândia, MG, aponta como pontos mais relevantes a insegurança, a dificuldade de cruzamento da via, o desestímulo ao uso de passarelas, a alteração na quantidade de viagens por indivíduo e a alteração da qualidade ambiental ao redor da via de estudo. Além disso, o estudo indica que a velocidade e o volume do tráfego estão diretamente associados à insegurança, enquanto a alteração da qualidade ambiental é provocada, principalmente, pelo aumento do ruído e da fumaça causada pelos veículos.

O Plano Diretor de Mobilidade (PlanMob) (MINISTÉRIO..., 2015) apresenta que as viagens realizadas a pé e por bicicleta correspondem ao maior número de deslocamentos nas cidades com população superior a 60 mil habitantes; este valor é ainda maior em cidades menores. No entanto, muitas vezes esses deslocamentos são prejudicados devido a decisões de planejamento de sistemas de transportes que promovem o uso de transportes individuais motorizados. $\mathrm{O}$ tráfego de pessoas (pedestres, cadeirantes, idosos, gestantes ou pessoas com mobilidade reduzida) deve ser planejado a fim de assegurar as condições de segurança, a conectividade e o conforto; também deve existir infraestrutura adequada e gestão do tráfego motorizado para facilitar o deslocamento do indivíduo (MINISTÉRIO..., 2015). Além disso, as estatísticas sobre acidentes de trânsito mostram que a segurança é um problema para os deslocamentos a pé, e uma maneira de solucionar isso é melhorando a infraestrutura para pedestres e reduzindo os conflitos com os vários tipos de veículos (MINISTÉRIO..., 2015), situações estas que são características do efeito barreira.

Os pedestres são os usuários dos sistemas de transportes mais expostos e vulneráveis a acidentes de trânsito (MINISTÉRIO..., 2015; CANTILlO; ARELLANA; ROLONG, 2015). Segundo Cantillo, Arellana e 
Rolong (2015), as alternativas propostas pelos planejadores para redução dos acidentes, como passarelas e faixas de pedestres em cruzamentos sinalizados, geralmente implicam distâncias mais longas em comparação com travessias diretas, que, por sua vez, envolvem risco maior. Em um estudo de preferência declarada em áreas urbanas da Inglaterra, Anciaes, Jones e Metcalfe (2018) mostram que 69\% dos entrevistados optam por não atravessar a rua devido à falta de segurança e perigo. Além disso, as dificuldades com relação à travessia também são advindas do tempo disponível de verde para pedestres (quando existe semáforo para pedestres) e da acessibilidade (altura dos botões do semáforo e existência de rampas para descida das calçadas às vias) (ANCIAES; JONES; METCALFE, 2018).

A dificuldade ou incapacidade de atravessar ruas é um dos impactos negativos que influencia diretamente nos deslocamentos a pé dos indivíduos (ANCIAES; JONES; METCALFE, 2018). Os idosos e as pessoas com mobilidade reduzida são os grupos sociais mais prejudicados nessa questão (MACKETT; TITHERIDGE; ACHUTHAN, 2010). Além disso, o estudo realizado por Lara (2019) mostra que os níveis de mobilidade urbana dos pedestres podem variar de acordo com fatores socioeconômicos (idade, renda, restrições de mobilidade e sexo).

Uma abordagem analítica para avaliação do efeito barreira com base na classificação da qualidade das passagens para pedestres em ferrovias e ruas urbanas foi proposta por Lara (2019). A autora apresentou dois estudos de caso que compreenderam infraestruturas ferroviárias e vias urbanas localizadas em São Carlos, SP, cidade brasileira de porte médio. As infraestruturas de transporte e a qualidade das passagens para pedestres foram estudadas e caracterizadas com base em dados agregados espacialmente. Como os dados agregados se referem a valores médios, não é possível capturar a percepção dos indivíduos tão precisamente quanto em uma pesquisa baseada em dados desagregados.

Em vista disso, a proposta do presente estudo é analisar, por meio de dados desagregados obtidos em questionários, evidências de que uma via de elevado tráfego de veículos motorizados localizada na mesma cidade estudada por Lara (2019) atue como barreira para os deslocamentos dos pedestres pela região, justamente em busca de preencher a lacuna existente nos estudos já realizados. Além disso, com a perspectiva de efetuar uma comparação dos resultados com os de outras cidades, a metodologia proposta foi baseada no questionário sobre as condições de saúde, bem-estar e mobilidade das pessoas de determinada região desenvolvido por Mindell et al. (2017).

\section{Materiais e métodos}

Este estudo visa avaliar, por meio de entrevistas, se uma via urbana de tráfego intenso em uma cidade média constitui uma barreira aos deslocamentos a pé das pessoas que residem e frequentam a região. Os dados coletados são avaliados usando uma análise descritiva e quantitativa. Além disso, são verificadas evidências de associações entre as dificuldades enfrentadas pelos entrevistados ao andar a pé pela região e suas características individuais e percepções do efeito barreira usando testes Qui-quadrado de independência $\left(\chi^{2}\right)$. Nesta seção apresenta-se a caracterização da via urbana, assim como a coleta de dados, as questões do questionário selecionadas para análise e os procedimentos de análise.

\section{Área de estudo e cálculo amostral}

O município de São Carlos, SP, possui população estimada de 251.983 pessoas, densidade demográfica de $195,15 \mathrm{hab} . / \mathrm{km}$ e área territorial urbana de aproximadamente $80 \mathrm{~km}$ na sede do município (INSTITUTO..., 2020; PREFEITURA..., 2020). Segundo a Fundação Sistema Estadual de Análise de Dados (FUNDAÇÃO..., 2020), 16,7\% de sua população têm idade inferior a 15 anos e 16,8\% têm idade superior a 60 anos, sendo aproximadamente $100 \%$ da população atendida com serviços de coleta de lixo, abastecimento de água e tratamento de esgoto sanitário. Além disso, segundo a mesma fonte, a taxa de analfabetismo da população é de $3,7 \%$, e cerca de $67 \%$ dos indivíduos entre 18 e 24 anos têm ensino médio completo, comparado a uma taxa de 57,9\% para o estado de São Paulo.

A área selecionada para o estudo compreende um trecho de cerca de 1,5 km da Rua Miguel Petroni (Figura 1), via urbana com intenso tráfego de veículos motorizados e $4,9 \mathrm{~km}$ de comprimento no total. $\mathrm{O}$ trecho foi selecionado por apresentar volume de tráfego que varia entre médio e alto (600 e 1.000 veículos por hora) (SECRETARIA..., 2002) e representar um desafio para a movimentação de pedestres e ciclistas, principalmente nos horários de pico. A Rua Miguel Petroni é caracterizada como principal, o sentido de tráfego é mão única, e, segundo o Departamento Nacional de Infraestrutura de Transportes 
(DEPARTAMENTO... 2010), trata-se de uma via arterial secundária, com velocidade máxima permitida variando entre $50 \mathrm{~km} / \mathrm{h}$ e $60 \mathrm{~km} / \mathrm{h}$.

Ainda sobre a região de estudo, segundo dados disponíveis no website da Secretaria de Segurança Pública do Estado de São Paulo (SECRETARIA..., 2017), a taxa de crimes/1.000 habitantes na região é 9,876, ante 16,485 do município em geral, e a taxa de homicídios/1.000 habitantes dela é 0,067, enquanto a de São Carlos é de 0,274. Portanto, a região da Rua Miguel Petroni apresenta índices de criminalidade e de homicídio inferiores aos índices totais da cidade. Sobre o uso do solo, a região divide-se entre residências e comércios de bens e serviços. Além disso, embora em alguns locais apresente semáforos e faixas de pedestres, como demonstrado na Figura 2, são comuns reclamações da população sobre a dificuldade de travessia na via e ocorrência de situações que apresentem perigo aos pedestres $(\mathrm{G} 1,2015$; SÃO CARLOS..., 2018).

Figura 1 - Localização da Rua Miguel Petroni (São Carlos, SP) e da área de estudo

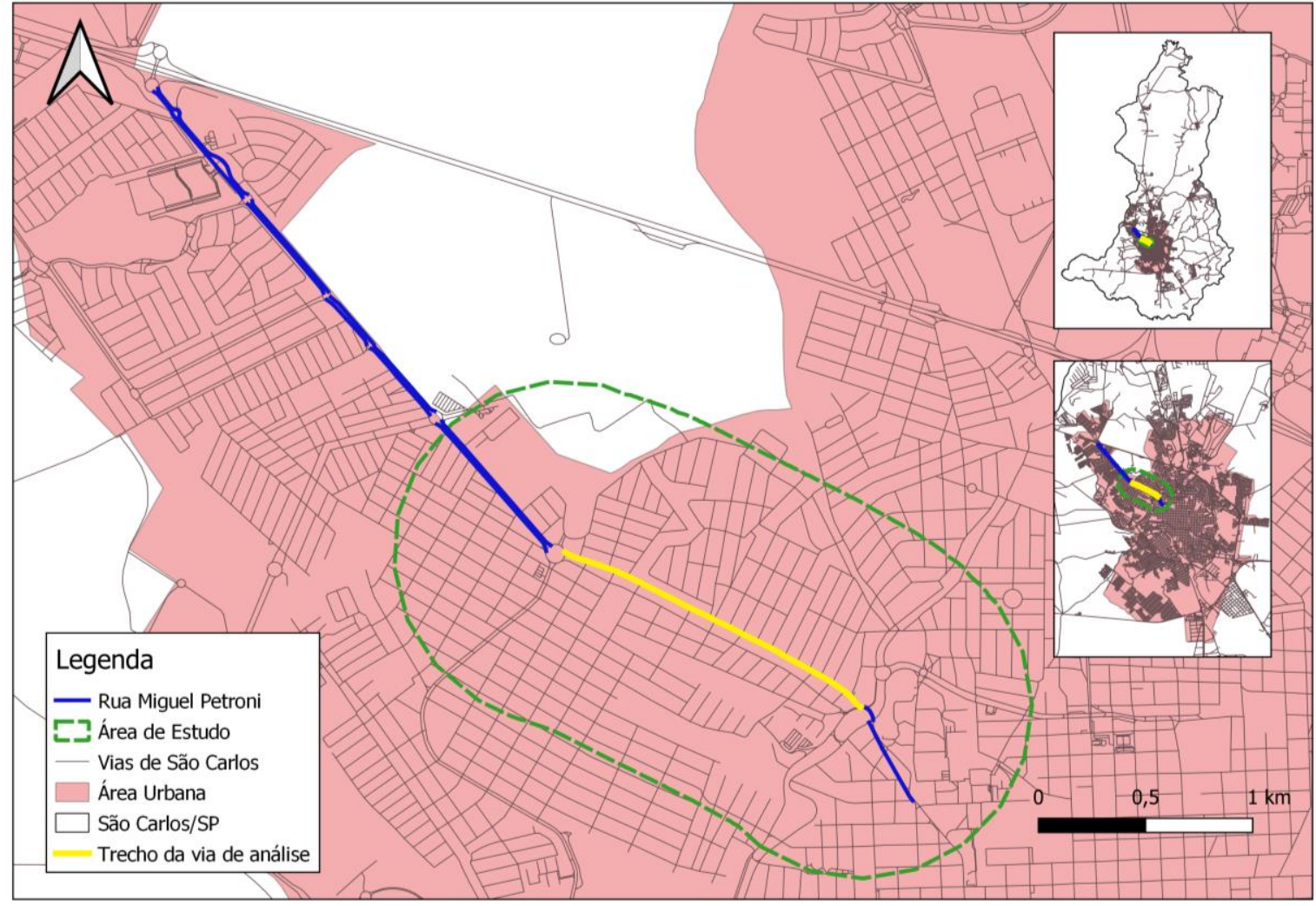

Figura 2 - Uso do solo na área de estudo
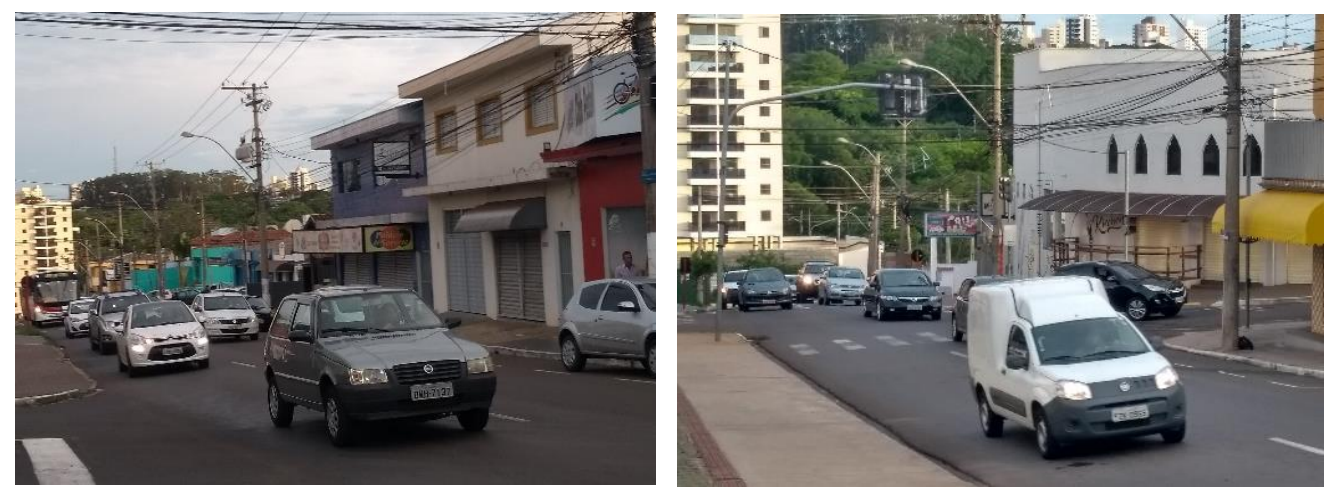
Os dados censitários do IBGE de 2010 (INSTITUTO..., 2020) permitem ainda estimar que cerca de 15 mil habitantes residem em uma faixa de área distante em $800 \mathrm{~m}$ do trecho de seleção da via de estudo, demarcada na Figura 1, distância adotada por ser considerada razoável para os deslocamentos locais, inclusive a pé. Dessa forma, para garantir que a amostra coletada tenha representatividade estatística, considerando nível de confiança de $95 \%$ e erro amostral igual a 0,10 , tem-se a quantidade amostral mínima de 96 pessoas. A amostra coletada para esta pesquisa tem perfil não probabilístico, visto que, para atingir a quantidade de questionários propostos, não foi feito sorteio de todas as residências e comércios presentes na área de estudo. Nesse sentido, pode ser tratada como uma amostra por conveniência.

\section{Coleta de dados}

Para avaliar se a via selecionada constitui uma barreira que interfere significativamente nos deslocamentos, nos acessos aos bens e serviços e no bem-estar da população, foi aplicado questionário com 37 questões e um espaço para opinião, como mostrado no Quadro 1. A formulação do questionário foi baseada no questionário desenvolvido por Mindell et al. (2017). A aplicação dos questionários por meio de entrevistas a moradores, trabalhadores e frequentadores da área de estudo foi aprovada pelo Comitê de Ética em Pesquisa em Seres Humanos da Universidade Federal de São Carlos, sob o Parecer nº 4.043.848, de 2020.

As entrevistas, com cerca de 20 min de duração, foram realizadas pessoalmente, com o apoio de dispositivo eletrônico (smartphone) devido à conveniência para a coleta e a padronização dos dados. A coleta foi executada somente em voluntários com idade superior a 17 anos que tivessem realizado ao menos uma viagem a pé por dia na semana anterior à qual foi realizada a entrevista (semana de referência). A abordagem dos entrevistados foi realizada em casas, em apartamentos, em estabelecimentos comerciais locais e nas ruas, em horário comercial (entre $8 \mathrm{~h} 00$ e 18h00), de segunda-feira a sexta-feira.

O questionário, desenhado para permitir diversas análises, foi dividido em quatro partes:

(a) caracterização do entrevistado (idade, formação acadêmica, renda, endereço, estado de saúde, etc.);

(b) interações sociais (contato com vizinhos, integração à região, confiabilidade das pessoas, medo de caminhar sozinho durante a noite, limpeza da região, etc.);

(c) viagens e mobilidade (dificuldades de caminhar, deficiências, quantidade de viagens a pé e duração delas, existência de faixa de pedestres, se a velocidade e o volume do tráfego representam barreiras para atingir algum destino caminhando, caracterização da rua onde mora e da rua próxima que considera mais movimentada, etc.); e

(d) espaço aberto para o respondente expor sua opinião (nesta parte as respostas foram gravadas em áudio).

Apesar de o questionário cobrir os diversos aspectos mencionados no item anterior, neste estudo foram apenas utilizados dados de questões específicas, como as da parte (a), sobre as características individuais dos entrevistados e da parte (c), sobre as dificuldades existentes no deslocamento a pé (questão 22 no Quadro 1, bem como no Quadro 2) e percepção do efeito barreira (questão 26). As respostas às questões da parte (c) permitem caracterizar se a via selecionada atua como barreira aos deslocamentos a pé da população no entorno da região de estudo. Além disso, essas respostas possibilitam verificar se existem evidências de associação entre as dificuldades enfrentadas pelos pedestres ao andar a pé pela região e suas percepções da velocidade ou do volume de tráfego dos veículos motorizados. Ademais, quando analisadas em conjunto, as respostas às questões das partes (a) e (c) permitem investigar se existem evidências de associação entre as dificuldades enfrentadas pelos pedestres e suas características individuais.

\section{Procedimentos de análise}

A análise das questões em que os entrevistados foram indagados sobre as dificuldades encontradas ao andar a pé pela região, bem como se a velocidade e o volume do tráfego impedem ou dificultam que eles atinjam seus destinos caminhando, permitiu avaliar se a via urbana analisada atua como uma barreira para a região, conforme indicado no Quadro 2. Em seguida, após uma análise exploratória para caracterização dos indivíduos e das demais respostas obtidas, foi aplicado o teste Qui-quadrado $\left(\chi^{2}\right)$ de independência para tentar identificar possíveis associações entre as variáveis e, assim, indícios de fatores que afetam os deslocamentos a pé da população na região de estudo. 
Quadro 1 - Configuração do questionário (Continua...)

\begin{tabular}{|c|c|c|}
\hline CATEGORIA & TIPO & QUESTÃO \\
\hline \multirow{10}{*}{$\begin{array}{l}\text { PARTE 1: } \\
\text { CARACTERIZA- } \\
\text { ÇÃO }\end{array}$} & \multirow{10}{*}{$\begin{array}{l}\text { Múltipla } \\
\text { escolha }\end{array}$} & 1. $\quad$ Sexo \\
\hline & & 2. Idade \\
\hline & & 3. Formação \\
\hline & & 4. $\quad$ Situação do imóvel \\
\hline & & 5. $\quad$ Endereço \\
\hline & & 6. Há quanto tempo você mora no seu atual endereço? \\
\hline & & 7. Há quanto tempo você mora nesta região da cidade? \\
\hline & & 8. Quantidade de veículos (carros e motos) \\
\hline & & 9. $\quad$ Renda \\
\hline & & 10. Estado de saúde \\
\hline \multirow[b]{3}{*}{$\begin{array}{l}\text { PARTE 2: } \\
\text { INTERAÇÕES } \\
\text { SOCIAIS }\end{array}$} & \multirow{2}{*}{$\begin{array}{l}\text { Múltipla } \\
\text { escolha }\end{array}$} & $\begin{array}{l}\text { 11. Quantos são os apartamentos ou casas no MESMO lado da rua onde } \\
\text { você mora em que moram vizinhos que você CONHECE? } \\
\text { 12. E do OUTRO lado? }\end{array}$ \\
\hline & & $\begin{array}{l}\text { 13. Com que frequência você visita seus vizinhos? } \\
\text { 14. Com que frequência você tem contato com seus vizinhos }\end{array}$ \\
\hline & $\begin{array}{c}\text { Escala de } 5 \\
\text { pontos }\end{array}$ & $\begin{array}{l}\text { 15. Qual sua opinião sobre as redondezas de onde você mora, ou seja, } \\
\text { região afastada até } 10 \text { minutos a pé de onde você mora? } \\
\text { - } \quad \text { Eu me sinto perfeitamente integrado/a nesta região } \\
\text { - } \quad \text { Vandalismo e pichações são um grande problema nesta região } \\
\text { - } \quad \text { A maioria das pessoas desta região é confiável } \\
\text { - } \quad \text { As pessoas têm medo de caminhar sozinhas à noite nesta região } \\
\text { - A maioria das pessoas desta região é amigável } \\
\text { - } \quad \text { As pessoas desta região vão tirar proveito de você } \\
\text { - } \quad \text { Se você estivesse com algum problema, as pessoas desta região iriam } \\
\quad \text { lhe ajudar }\end{array}$ \\
\hline \multirow[b]{3}{*}{$\begin{array}{l}\text { PARTE 3: } \\
\text { VIAGENS E } \\
\text { MOBILIDADE }\end{array}$} & \multirow[t]{2}{*}{$\begin{array}{l}\text { Múltipla } \\
\text { escolha }\end{array}$} & $\begin{array}{l}\text { 16. Você tem alguma dificuldade permanente de caminhar ou subir degraus } \\
\text { (sem o auxílio de outra pessoa)? } \\
\text { 17. Você tem alguma deficiência motora permanente que dificulte: sair a } \\
\text { pé, usar ônibus, usar veículos? } \\
\text { 18. Você tem alguma deficiência permanente que limite as suas atividades } \\
\text { de alguma outra forma (subir escadas, equilíbrio)? }\end{array}$ \\
\hline & & $\begin{array}{l}\text { 19. Em média, quantas viagens a pé você costuma realizar por dia? } \\
\text { 20. Em média, quanto tempo duram estas viagens? }\end{array}$ \\
\hline & $\begin{array}{c}\text { Escala de } 5 \\
\text { pontos }\end{array}$ & $\begin{array}{l}\text { 21. Indique o seu grau de concordância com as seguintes afirmações } \\
\text { sobre preferência de travessia, em geral. } \\
\text { - } \quad \text { Me sinto mais seguro em ruas com maior movimento de pessoas } \\
\text { - } \quad \text { Me sinto mais seguro em ruas com maior movimento de veículos } \\
\text { - } \quad \text { Evito circular por ruas com pouco movimento de pessoas ou veículos } \\
\text { - } \quad \text { Pela manhã e/ou à tarde, eu prefiro caminhar por ruas onde há } \\
\text { estabelecimentos comerciais } \\
\text { - } \quad \text { Pela manhã e/ou à tarde, eu prefiro caminhar por ruas onde há } \\
\text { residências } \\
\text { - Não tenho problemas em caminhar por ruas com muito lixo e vegetação } \\
\text { - } \quad \text { Prefiro atravessar em locais onde há semáforo } \\
\text { - } \quad \text { Prefiro atravessar em locais onde há faixa de pedestre } \\
\text { - Prefiro atravessar quando há oportunidade, independentemente de ser } \\
\text { - } \quad \text { fora da faixa de pedestres ou semáforo } \\
\text { - As faixas de pedestres da rua mais movimentada perto de onde moro } \\
\text { são bem localizadas, sempre as utilizo }\end{array}$ \\
\hline
\end{tabular}




\section{Quadro 1 - Configuração do questionário (continuação)}

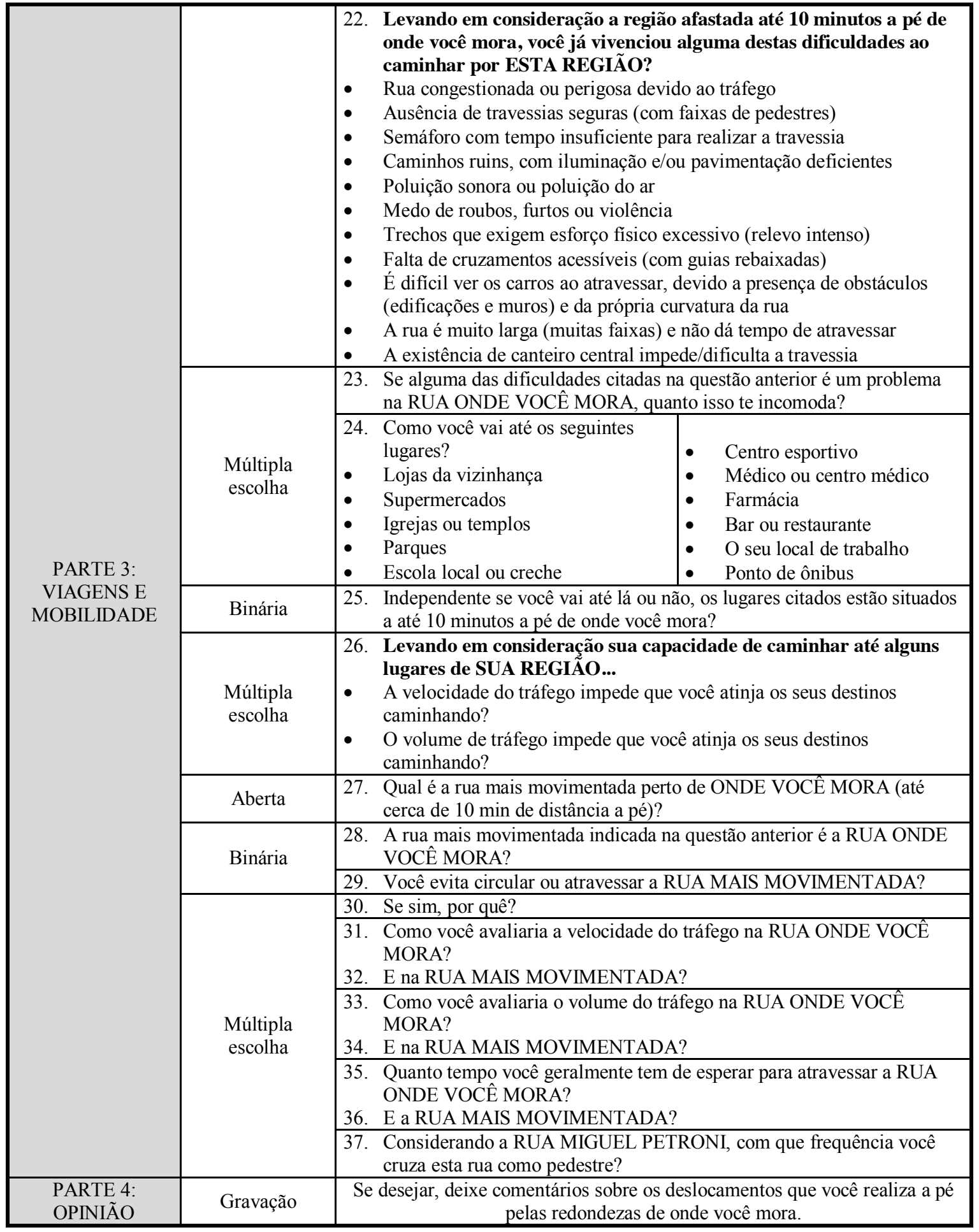


Quadro 2 - Questões utilizadas para avaliar se a Rua Miguel Petroni (São Carlos, SP) compreende uma barreira para o deslocamento de pedestres

\begin{tabular}{|l|l|}
\hline \multicolumn{1}{|c|}{ Questões } & \multicolumn{1}{|c|}{ Alternativas } \\
\hline & ( ) Nunca \\
QUESTÃo 26 - A VELOCIDADE/VOLUME IMPEDE QUE & ( ) Raramente \\
VOCÊ ATINJA SEUS DESTINOS CAMINHANDO? & ( ) Às vezes \\
( ) Geralmente \\
QUESTÃO 22 - VOCÊ JÁ VIVENCIOU ALGUMA DESSAS & ( ) Sempre \\
DIFICULDADES NOS DESLOCAMENTOS A PÉ? & ( ) Não \\
\hline
\end{tabular}

O teste de independência empregado é um teste de hipótese amplamente utilizado para comparar proporções e avaliar a associação entre variáveis categóricas. A partir de tabelas de contingência das variáveis estudadas, calcula-se o valor de Qui-quadrado pela Equação 1 (AGRESTI, 2007; YATES, 1934) e seu respectivo $p$-valor. A partir do nível de confiança adotado e dos graus de liberdade da tabela de contingência, encontram-se os valores críticos de $\chi^{2}$. Por fim, comparando-se os valores calculados com os valores críticos, é possível aceitar ou rejeitar a hipótese nula $\left(\mathrm{H}_{0}\right)$ de independência entre as variáveis e verificar o grau de dependência entre elas.

$\chi^{2}=\sum \frac{(\text { Observado-Esperado })^{2}}{\text { Esperado }}$

Eq. 1

Em que:

$\chi^{2}$ : Qui-quadrado;

Observado: valores correspondentes aos coletados; e

Esperado: valores correspondentes aos esperados.

Além disso, foi calculado o valor residual padronizado de Pearson (Standardized Pearson Residuals - SPR), mostrado na Equação 2 (AGRESTI, 2007). O SPR compara as células da tabela de contingência, mostrando o grau de dependência entre as variáveis e qual a que mais contribui para o resultado final do teste de $\chi^{2}$. Segundo Agresti (2007), para tabelas pequenas, um valor de SPR que exceda o valor 2 indica que a célula contribui muito para o valor do $\chi^{2}$ e não se ajusta a $\mathrm{H}_{0}$.

$S P R=\frac{\text { Observado-Esperado }}{\sqrt{\left(\text { Esperado } *\left(1-\frac{\text { Ltotal }}{\text { Total }}\right) *\left(1-\frac{\text { Ctotal }}{\text { Total }}\right)\right.}}$

Eq. 2

Em que:

SPR: Standardized Pearson Residuals;

$L_{\text {total }}$ : soma das contagens observadas na linha;

$C_{\text {total }}$ : soma das contagens observadas na coluna; e

Total: soma de todas as contagens observadas.

Os resultados obtidos, mostrados na próxima seção, permitem avaliar se a Rua Miguel Petroni constitui uma barreira aos deslocamentos dos pedestres e se há evidências de associação entre as dificuldades presentes nos deslocamentos a pé e as características individuais, e a percepção da velocidade e/ou do volume do tráfego.

\section{Resultados}

Embora alguns estudos tenham nos últimos anos se dedicado a medir o efeito barreira relacionado aos sistemas de transportes, tal como caracterizado por Mindell et al. (2017), na vida social da população e na capacidade dos indivíduos de usufruir de bens e serviços (ANCIAES et al., 2016; LARA, 2019; LARA; RODRIGUES DA SILVA, 2018; NIMEGEER et al., 2018; SILVA JUNIOR; FERREIRA, 2008; VAN ELDIJK et al., 2020), tais estudos ainda estão limitados em termos de quantidade e abrangência. Um contexto específico que ainda carece de investigação é o caso das cidades médias, foco do presente estudo. Neste estudo, o caso de uma via urbana localizada na cidade de São Carlos, SP, é analisado por meio de 
dados desagregados baseados na percepção dos indivíduos potencialmente afetados, conforme se descreve na sequência.

\section{Caracterização da amostra e da percepção sobre o efeito barreira}

Neste estudo foram realizadas entrevistas em março de 2020 com moradores, trabalhadores e frequentadores da Rua Miguel Petroni, situados numa área de influência de $800 \mathrm{~m}$ no entorno da via. No total, foram coletadas 103 respostas válidas. Os entrevistados tinham 18 anos ou mais e eram de ambos os sexos. A distribuição de endereços dos entrevistados é indicada na Figura 3. Em uma análise preliminar dos dados coletados, observa-se que $66,0 \%$ dos respondentes são do sexo feminino, predominantemente entre 30 e 59 anos e com renda mensal de até 3 salários mínimos. Mais de 80,0\% têm ensino médio completo $(55,3 \%$ estão cursando ou já concluíram o ensino superior), uma característica particular da região de estudo. Além disso, $86,4 \%$ consideram o próprio estado de saúde excelente ou bom, como exibido na Tabela 1.

As respostas às questões que permitem caracterizar se a via selecionada atua como uma barreira para a região de estudo estão resumidas na Tabela 1. Essas respostas foram discriminadas pelas características dos indivíduos. As respostas das demais perguntas selecionadas, aquelas em que os entrevistados apontam as dificuldades encontradas ao andar a pé pela região (tais como a existência de rua congestionada ou perigosa devido ao tráfego, travessias inseguras, tempo do semáforo inadequado, poluição sonora ou do ar), são detalhadas na Tabela 2. Mediante as 103 respostas obtidas, observa-se que 55,3\% e 56,3\% dos entrevistados consideram em algum nível (raramente, às vezes, geralmente e sempre), respectivamente, a velocidade e o volume do tráfego um empecilho para seus deslocamentos a pé. Ou seja, a via analisada impediu ou dificultou que em algum momento os usuários atingissem seus destinos caminhando. Observa-se ainda na Tabela 1 detalhes por subgrupo, como o caso dos respondentes com estado de saúde RAzOÁVEL/RUIM, que consideram com mais frequência a velocidade do tráfego motorizado como uma barreira.

\section{Associação entre variáveis}

A partir dos dados referentes às possíveis dificuldades encontradas nos deslocamentos a pé, às características individuais dos respondentes e à percepção dos usuários da velocidade e do volume do tráfego na região, foram elaboradas tabelas de contingências e aplicado o teste Qui-quadrado de independência. A princípio, os testes foram realizados entre as variáveis referentes às características dos respondentes e às perguntas sobre a percepção do efeito barreira, no entanto não foram encontrados indícios de associação entre essas variáveis. Ou seja, parece não existir associação entre a percepção do efeito barreira na via de estudo e as características individuais dos entrevistados com base apenas na velocidade e no volume de tráfego. Isso não significa, no entanto, que ocorra o mesmo em relação a cada uma das dificuldades para o deslocamento.

\section{Dificuldades para deslocamento a pé e características individuais dos entrevistados}

As características individuais dos respondentes foram confrontadas com as 11 alternativas binárias componentes da questão relacionada às dificuldades na realização de percursos a pé (Quadro 2), como mostrado na Tabela 2. Os resultados que apresentam associação com níveis de significância de $0,05(\alpha=5 \%)$ e $0,10(\alpha=10 \%)$ foram destacados na Tabela 2 com escalas de cinza escuro e cinza claro respectivamente.

Para um nível de significância de 0,05 , os dados não permitem descartar associação entre a característica SEXO e as dificuldades poluição sonora ou do ar e trechos que exigem esforço físico excessivo como empecilho para a travessia. Para esse mesmo nível de significância há indícios de associação entre a IDADE e a FORMAÇÃO ACADÊMICA com caminhos ruins, com iluminação elou pavimentação deficientes. Foi também verificado um $p$-valor inferior a 0,05 para as características do IMÓVEL e as dificuldades medo de roubos, furtos ou violência e trechos que exigem esforço físico excessivo. Ainda considerando o nível de significância citado, não se pode descartar associação entre RENDA e a presença de obstáculos que dificultam ver os carros ao atravessar; e entre ESTADO DE SAÚDE e semáforo com tempo insuficiente para realizar a travessia. Além disso, considerando o nível de significância de $0,10(\alpha=10 \%)$, os dados não permitem descartar associação entre as características relacionadas a SEXO e IMÓVEL com a dificuldade rua congestionada ou perigosa devido ao tráfego. Foi verificado também um $p$-valor inferior a 0,10 para associação entre ESTADO DE SAÚDE e falta de cruzamentos acessíveis como uma dificuldade para a travessia. 
Figura 3 - Distribuição dos endereços (localização aproximada, de forma a preservar a privacidade dos respondentes) dos 103 entrevistados

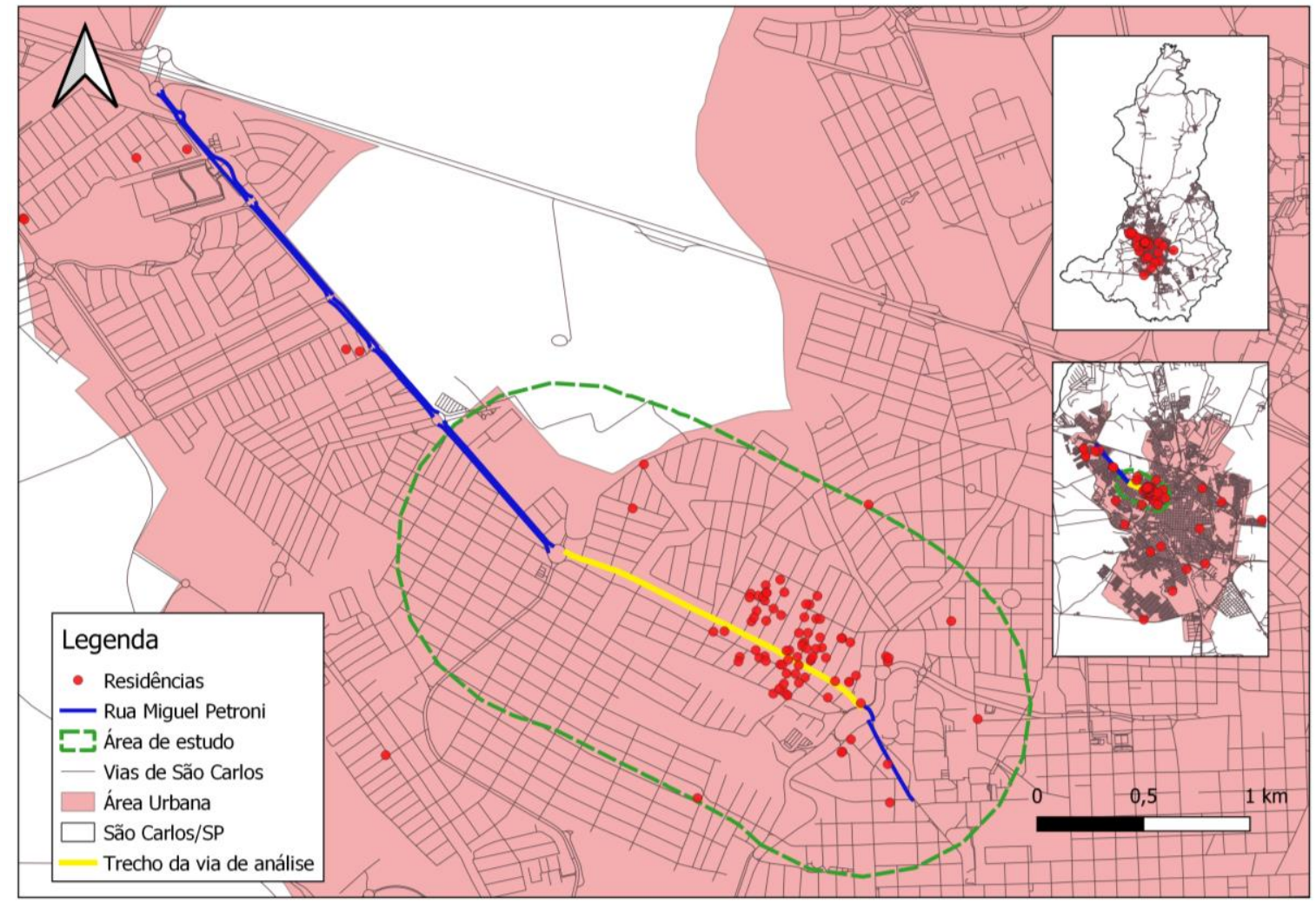

Tabela 1 - Caracterização da amostra e associação das CARACTERÍSTICAS INDIVIDUAIS com a percepção do efeito barreira baseado na velocidade e no volume do tráfego

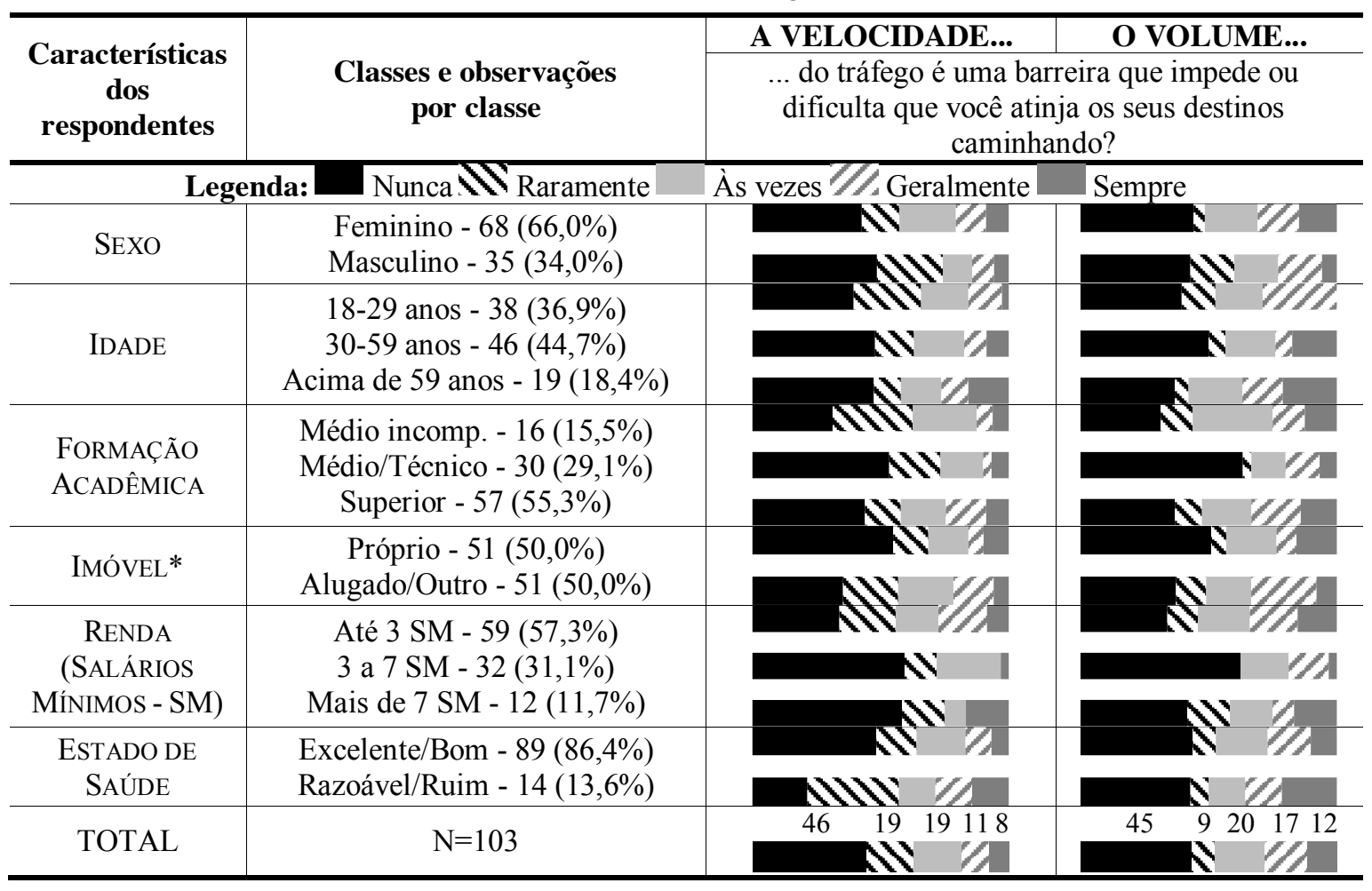

Nota: *um entrevistado optou por não responder a esta pergunta, neste caso $\mathrm{N}=102$. 
Tabela 2 - Quantidade de pessoas que apontou cada dificuldade presente no deslocamento a pé em relação ao total de cada classe das características individuais

\begin{tabular}{|c|c|c|c|c|c|c|c|c|}
\hline \multirow{3}{*}{$\begin{array}{c}\text { Dificuldades para } \\
\text { deslocamento a pé }(\mathrm{N}=\mathbf{1 0 3})\end{array}$} & \multicolumn{8}{|c|}{ Características dos respondentes } \\
\hline & \multicolumn{2}{|c|}{ Sexo } & \multicolumn{3}{|c|}{ Idade } & \multicolumn{3}{|c|}{ Formação } \\
\hline & $\begin{array}{l}\text { Fem. } \\
(\mathbf{6 8})\end{array}$ & $\begin{array}{l}\text { Masc. } \\
\text { (35) }\end{array}$ & $\begin{array}{c}18-29 \\
(38)\end{array}$ & $\begin{array}{c}30-59 \\
(46)\end{array}$ & $\begin{array}{l}60+ \\
\text { (19) }\end{array}$ & \begin{tabular}{l|} 
Bás. \\
(16)
\end{tabular} & $\begin{array}{l}\text { Méd. } \\
\text { (30) }\end{array}$ & $\begin{array}{l}\text { Sup. } \\
(\mathbf{5 7})\end{array}$ \\
\hline $\begin{array}{l}\text { Rua congestionada/perigosa } \\
\text { devido ao tráfego (70) }\end{array}$ & $50^{1}$ & 20 & 26 & 30 & 14 & 9 & 21 & 40 \\
\hline $\begin{array}{l}\text { Ausência de travessias seguras } \\
\text { (68) }\end{array}$ & 47 & 21 & 25 & 28 & 15 & 8 & 18 & 42 \\
\hline $\begin{array}{l}\text { Semáforo insuficiente para } \\
\text { travessia (14) }\end{array}$ & 10 & 4 & 5 & 5 & 4 & 3 & 4 & 7 \\
\hline $\begin{array}{l}\text { Caminhos ruins (iluminação } \\
\text { e/ou pavimentação) (67) }\end{array}$ & 45 & 22 & $32^{2}$ & 24 & 11 & $4^{3}$ & 20 & 43 \\
\hline $\begin{array}{l}\text { Poluição sonora ou poluição do } \\
\text { ar (41) }\end{array}$ & $32^{4}$ & 9 & 15 & 16 & 10 & 6 & 9 & 26 \\
\hline $\begin{array}{l}\text { Medo de roubos, furtos ou } \\
\text { violência (69) }\end{array}$ & 47 & 22 & 29 & 28 & 12 & 10 & 17 & 42 \\
\hline $\begin{array}{l}\text { Trechos que exigem esforço } \\
\text { físico excessivo (42) }\end{array}$ & $35^{5}$ & 7 & 18 & 16 & 8 & 5 & 10 & 27 \\
\hline $\begin{array}{l}\text { Falta de cruzamentos acessíveis } \\
\text { (49) }\end{array}$ & 34 & 15 & 20 & 20 & 9 & 7 & 16 & 26 \\
\hline $\begin{array}{l}\text { É difícil ver os carros ao } \\
\text { atravessar (34) }\end{array}$ & 24 & 10 & 14 & 12 & 8 & 4 & 9 & 21 \\
\hline $\begin{array}{l}\text { A rua é muito larga e não dá } \\
\text { tempo de atravessar (12) }\end{array}$ & 7 & 5 & 3 & 7 & 2 & 2 & 2 & 8 \\
\hline \multirow{3}{*}{$\begin{array}{l}\text { Dificuldades para } \\
\text { deslocamento a pé }(\mathrm{N}=\mathbf{1 0 3})\end{array}$} & \multicolumn{8}{|c|}{ Características dos respondentes } \\
\hline & \multicolumn{2}{|c|}{ Imóvel* } & \multicolumn{4}{|c|}{\begin{tabular}{|l|l} 
Renda (Sal. Mínimos) & \\
\end{tabular}} & \multicolumn{2}{|c|}{ Est. Saúde } \\
\hline & $\begin{array}{l}\text { Próp. } \\
\text { (51) }\end{array}$ & $\begin{array}{c}\text { Outro } \\
(\mathbf{5 1})\end{array}$ & $\begin{array}{c}-3 \\
(\mathbf{5 9}) \\
\end{array}$ & $\begin{array}{l}3-7 \\
(32) \\
\end{array}$ & $\begin{array}{c}7+ \\
(12) \\
\end{array}$ & $\begin{array}{c}\text { Bom/Exc } \\
(\mathbf{8 9})\end{array}$ & & $\begin{array}{l}\text { Ruim } \\
\text { (14) }\end{array}$ \\
\hline $\begin{array}{l}\text { Rua congestionada/perigosa } \\
\text { devido ao tráfego (70) }\end{array}$ & $31^{6}$ & 39 & 41 & 20 & 9 & 61 & & 9 \\
\hline $\begin{array}{l}\text { Ausência de travessias seguras } \\
\text { (68) }\end{array}$ & 36 & 31 & 35 & 24 & 9 & 61 & & 7 \\
\hline $\begin{array}{l}\text { Semáforo insuficiente para } \\
\text { travessia (14) }\end{array}$ & 6 & 8 & 8 & 5 & 1 & $8^{7}$ & & 6 \\
\hline $\begin{array}{l}\text { Caminhos ruins (iluminação } \\
\text { e/ou pavimentação) (67) }\end{array}$ & 31 & 36 & 38 & 22 & 7 & 60 & & 7 \\
\hline $\begin{array}{l}\text { Poluição sonora ou poluição do } \\
\operatorname{ar}(\mathbf{4 1})\end{array}$ & 23 & 18 & 27 & 10 & 4 & 35 & & 6 \\
\hline $\begin{array}{l}\text { Medo de roubos, furtos ou } \\
\text { violência (69) }\end{array}$ & $28^{8}$ & 40 & 44 & 17 & 8 & 60 & & 9 \\
\hline $\begin{array}{l}\text { Trechos que exigem esforço } \\
\text { físico excessivo (42) }\end{array}$ & $16^{9}$ & 26 & 23 & 13 & 6 & 35 & & 7 \\
\hline $\begin{array}{l}\text { Falta de cruzamentos acessíveis } \\
\text { (49) }\end{array}$ & 25 & 24 & 28 & 17 & 4 & $39^{10}$ & & 10 \\
\hline $\begin{array}{l}\text { É difícil ver os carros ao } \\
\text { atravessar (34) }\end{array}$ & 14 & 20 & $15^{11}$ & 16 & 3 & 31 & & 3 \\
\hline $\begin{array}{l}\text { A rua é muito larga e não dá } \\
\text { tempo de atravessar (12) }\end{array}$ & 6 & 6 & 4 & 5 & 3 & 9 & & 3 \\
\hline
\end{tabular}

Nota: células em cinza escuro e cinza claro mostram associação com de $\alpha=0,05$ e $a=0,10$ respectivamente.

*Um entrevistado optou por não responder a esta pergunta, neste caso $\mathrm{N}=102$.

p-valor: (1) 0,091 ; (2) 0,007 ; (3) 0,001 ; (4) 0,036; (5) 0,$02 ;(6) 0,088$; (7) 0,$001 ;(8) 0,012 ;(9) 0,044 ;(10) 0,055$;

(11) 0,048 


\section{Dificuldades para deslocamento a pé e percepção do tráfego motorizado}

Para esta análise, os entrevistados foram divididos entre dois grupos, os que consideram a velocidade e o volume do tráfego como barreira aos deslocamentos a pé, e os que não consideram. No grupo "sim" foram agrupados aqueles que responderam que "às vezes", "geralmente" ou "sempre" consideram a velocidade (36,9\% do total) e o volume do tráfego (47,6\% do total) como um impedimento para atingirem seus destinos caminhando. No grupo "não" foram agrupados os que responderam "raramente" e "nunca" para a mesma pergunta (63,1\% para a velocidade e $52,4 \%$ para o volume do tráfego).

Os resultados da aplicação do teste de independência das respostas dos dois grupos de respondentes com as dez alternativas binárias relacionadas às dificuldades na realização de percursos a pé (Quadro 2) estão resumidos nas Tabelas 3 e 4, nas quais são apresentados os valores observados, os valores esperados (entre parênteses) e os valores dos resíduos padronizados de Pearson (em negrito). Na Tabela 3 é possível observar um $p$-valor inferior a 0,05 para as variáveis poluição sonora e do ar, trechos que exigem esforço físico excessivo e ruas muito largas (não dando tempo para atravessar), o que sugere a associação delas com a variável velocidade do tráfego. É possível notar também evidência de associação entre a velocidade e rua perigosa devido ao tráfego e presença de obstáculos dificultando a visualização dos veículos circulando, nestes casos para um nível de significância de 0,10 .

De maneira geral, cerca de 60\% dos entrevistados (62 dos 103) dizem não ter problema com poluição sonora e do ar na região de estudo. No entanto, quando se analisa o grupo de pessoas que consideram a velocidade do tráfego uma barreira para que realizem deslocamentos a pé, 57,9\% destes se incomodam com a poluição. Além disso, um valor de $S P R$ maior do que 2,0 significa que as células têm valores observados muito acima ou muito abaixo dos valores esperados, o que contribui para um valor final elevado de Quiquadrado $\left(\chi^{2}\right)$ (Tabela 3$)$.

É possível observar um $p$-valor inferior a 0,05 (e um valor de $S P R$ maior do que 2,0) para as variáveis trechos que exigem esforço físico excessivo, falta de cruzamentos acessíveis e ruas muito largas, o que sugere associação delas com a variável volume do tráfego. Não se pode descartar ainda uma possível associação entre volume e poluição sonora e do ar, neste caso para um nível de significância de 0,10 (Tabela 4).

Com os dados coletados, observa-se que algumas das dificuldades abordadas no questionário são associadas concomitantemente à velocidade e ao volume do tráfego. Nota-se que, para um nível de significância de 0,05, não é possível descartar associação entre o tráfego de veículos motorizados e trechos que exigem esforço físico excessivo e largura das vias. Além disso, a variável poluição sonora e do ar também aparece como uma dificuldade associada tanto à velocidade quanto ao volume de tráfego, desta vez para nível de significância de 0,05 e 0,10 respectivamente.

Os dados coletados foram analisados por meio de estatística descritiva e teste Qui-quadrado de independência. Foi possível avaliar quais dificuldades presentes no deslocamento a pé possuem indícios de associação com a velocidade e/ou com o volume do tráfego. É possível identificar traços de que o tráfego de veículos motorizados na região de estudo interfere nos deslocamentos a pé e nas percepções sobre as dificuldades dos indivíduos como pedestres, principalmente por meio da associação entre as variáveis estudadas. A quantidade de respostas coletadas $(\mathrm{N}=103)$ é um fator que pode ter influenciado diretamente nos resultados, principalmente na associação entre as variáveis estudadas. Contudo, a coleta da amostra foi interrompida devido às recomendações de afastamento social em consequência da pandemia de covid-19, o que pode ser visto como uma limitação para a presente pesquisa (se fosse possível ampliar a amostra, o erro associado seria menor do que $10 \%$ ). Em alguns casos, com a quantidade de questionários respondidos, foi necessário realizar o agrupamento das alternativas dispostas aos entrevistados de forma que possibilitasse a aplicação do teste Qui-quadrado de independência. Em outros casos, não descritos neste estudo, não foi possível aplicar o teste devido à quantidade insuficiente de observações nas células da tabela de contingência. Devido a isso, posteriormente, após a flexibilização das recomendações de afastamento social, espera-se retomar a pesquisa e aplicar questionários a um maior número de moradores e frequentadores da região de estudo, além de associar o método de análise empregado com outras abordagens.

\section{Conclusão}

Nos últimos anos algumas pesquisas vêm buscando medir o efeito das infraestruturas de transporte como barreiras ao deslocamento, na vida social da população e na capacidade dos indivíduos de usufruir bens e serviços. Neste estudo foram coletados dados por meio de um questionário, aplicados a moradores e 
frequentadores da Rua Miguel Petroni (São Carlos, SP), com o propósito de avaliar se a via urbana atua como uma barreira aos deslocamentos dos pedestres. Para isso foi realizado o teste Qui-quadrado de independência em tabelas de contingência que relacionam as características individuais, a percepção do volume e da velocidade do tráfego a algumas condições que podem dificultar a locomoção a pé.

Dessa forma, foi possível identificar que a via urbana selecionada, a Rua Miguel Petroni, representa para a população uma barreira que interfere no deslocamento a pé dos indivíduos. Os impactos do efeito barreira nas caminhadas foram caracterizados, principalmente, pelas dificuldades enfrentadas pelos pedestres que apresentaram associação com as características individuais e percepções do efeito barreira com base na velocidade e/ou no volume do tráfego.

Tabela 3 - Teste $\chi^{2}$ entre a velocidade do tráfego e as dificuldades ao deslocamento a pé

\begin{tabular}{|c|c|c|c|c|}
\hline \multirow[b]{2}{*}{ Dificuldade } & \multicolumn{4}{|c|}{$\begin{array}{l}\text { A VELOCIDADE DO TRÁFEGO é uma barreira que impede ou } \\
\text { dificulta que você atinja os seus destinos caminhando } \\
\text { Observado (Esperado) [SPR] }\end{array}$} \\
\hline & Não & Sim & $\chi^{2}$ & $p$-valor \\
\hline $\begin{array}{l}\text { Rua congestionada ou perigosa } \\
\text { devido ao tráfego } \\
\text { Não } \\
\text { Sim }\end{array}$ & $\begin{array}{c}25(20,8)[\mathbf{1 , 8}] \\
40(44,2)[-\mathbf{1 , 8}]\end{array}$ & $\begin{array}{c}8(12,2)[\mathbf{- 1 , 8}] \\
30(25,8)[\mathbf{1}, \mathbf{8}]\end{array}$ & 3,338 & $0,068 * *$ \\
\hline $\begin{array}{l}\text { Ausência de travessias seguras } \\
\text { Não } \\
\text { Sim }\end{array}$ & $\begin{array}{c}21(22,1)[\mathbf{- 0 , 5}] \\
44(42,9)[\mathbf{0 , 5}]\end{array}$ & $\begin{array}{c}14(12,9)[\mathbf{0 , 5}] \\
24(25,1)[-\mathbf{0 , 5}]\end{array}$ & 0,220 & 0,639 \\
\hline $\begin{array}{l}\text { Semáforo com tempo insuficiente } \\
\text { para realizar a travessia } \\
\text { Não } \\
\text { Sim }\end{array}$ & $\begin{array}{c}57(56,2)[\mathbf{0 , 5}] \\
8(8,8)[\mathbf{- 0 , 5}]\end{array}$ & $\begin{array}{c}32(32,8)[-\mathbf{0 , 5}] \\
6(5,2)[\mathbf{0 , 5}]\end{array}$ & 0,248 & 0,619 \\
\hline $\begin{array}{l}\text { Caminhos ruins, com iluminação } \\
\text { e/ou pavimentação deficientes } \\
\text { Não } \\
\text { Sim }\end{array}$ & $\begin{array}{c}25(22,7)[\mathbf{1 , 0}] \\
40(42,3)[-\mathbf{1}, \mathbf{0}]\end{array}$ & $\begin{array}{l}11(13,3)[-\mathbf{1}, \mathbf{0}] \\
27(24,7)[\mathbf{1 , 0}]\end{array}$ & 0,955 & 0,329 \\
\hline $\begin{array}{l}\text { Poluição sonora ou poluição do ar } \\
\text { Não } \\
\text { Sim }\end{array}$ & $\begin{array}{c}46(39,1)[\mathbf{2 , 9}] \\
19(25,9)[-\mathbf{2 , 9}]\end{array}$ & $\begin{array}{l}16(22,9)[-\mathbf{2}, \mathbf{9}] \\
22(15,1)[\mathbf{2 , 9}]\end{array}$ & 8,223 & $0,004 *$ \\
\hline $\begin{array}{l}\text { Medo de roubos, furtos ou } \\
\text { violência } \\
\text { Não } \\
\text { Sim }\end{array}$ & $\begin{array}{c}23(21,5)[\mathbf{0 , 7}] \\
42(43,5)[-\mathbf{0 , 7}]\end{array}$ & $\begin{array}{l}11(12,5)[-\mathbf{0 , 7}] \\
27(25,5)[\mathbf{0 , 7}]\end{array}$ & 0,449 & 0,503 \\
\hline $\begin{array}{l}\text { Trechos que exigem esforço físico } \\
\text { excessivo } \\
\text { Não } \\
\text { Sim }\end{array}$ & $\begin{array}{c}45(38,5)[2,7] \\
20(26,5)[-2,7]\end{array}$ & $\begin{array}{l}16(22,5)[-2,7] \\
22(15,5)[2,7]\end{array}$ & 7,307 & $0,007 *$ \\
\hline $\begin{array}{l}\text { Falta de cruzamentos acessíveis } \\
\text { Não } \\
\text { Sim }\end{array}$ & $\begin{array}{c}38(34,1)[\mathbf{1 , 6}] \\
27(30,9)[-\mathbf{1}, \mathbf{6}]\end{array}$ & $\begin{array}{l}16(19,9)[-\mathbf{1}, \mathbf{6}] \\
22(18,1)[\mathbf{1 , 6}]\end{array}$ & 2,572 & 0,109 \\
\hline $\begin{array}{l}\text { É difícil ver os carros ao } \\
\text { atravessar devido à presença de } \\
\text { obstáculos e à curvatura da rua } \\
\text { Não } \\
\text { Sim }\end{array}$ & $\begin{array}{c}48(43,5)[\mathbf{1 , 9}] \\
17(21,5)[-\mathbf{1}, \mathbf{9}]\end{array}$ & $\begin{array}{c}21(25,5)[-\mathbf{1}, \mathbf{9}] \\
17(12,5)[\mathbf{1 , 9}]\end{array}$ & 3,745 & $0,053 * *$ \\
\hline $\begin{array}{l}\text { A rua é muito larga e não dá } \\
\text { tempo de atravessar } \\
\text { Não } \\
\text { Sim } \\
\end{array}$ & $\begin{array}{c}61(57,4)[\mathbf{2}, \mathbf{3}] \\
4(7,6)[-2,3] \\
\end{array}$ & $\begin{array}{c}30(33,6)[-2,3] \\
8(4,4)[\mathbf{2}, \mathbf{3}] \\
\end{array}$ & 5,171 & $0,023^{*}$ \\
\hline
\end{tabular}

Nota: evidência de associação para nível de significância de $0,05^{*}$ e $0,10^{* *}$ 
Tabela 4 - Teste $\chi^{2}$ entre o volume do tráfego e as dificuldades do deslocamento a pé

\begin{tabular}{|c|c|c|c|c|}
\hline \multirow[b]{2}{*}{ Dificuldade } & \multicolumn{4}{|c|}{$\begin{array}{c}\text { O VOLUME DO TRÁFEGO é uma barreira que impede ou dificulta } \\
\text { que você atinja os seus destinos caminhando } \\
\text { Observado (Esperado) [SPR] }\end{array}$} \\
\hline & Não & Sim & $\chi^{2}$ & $p$-valor \\
\hline $\begin{array}{l}\text { Rua congestionada ou perigosa } \\
\text { devido ao tráfego } \\
\text { Não } \\
\text { Sim } \\
\end{array}$ & $\begin{array}{c}18(17,3)[\mathbf{0 , 3}] \\
36(36,7)[\mathbf{- 0 , 3}]\end{array}$ & $\begin{array}{l}15(15,7)[\mathbf{- 0 , 3}] \\
34(33,3)[\mathbf{0 , 3}]\end{array}$ & 0,087 & 0,768 \\
\hline $\begin{array}{l}\text { Ausência de travessias seguras } \\
\text { Não } \\
\text { Sim }\end{array}$ & $\begin{array}{l}17(18,3)[\mathbf{- 0 , 6}] \\
37(35,7)[\mathbf{0 , 6}]\end{array}$ & $\begin{array}{r}18(16,7)[\mathbf{0 , 6}] \\
31(32,3)[-\mathbf{0 , 6}]\end{array}$ & 0,316 & 0,574 \\
\hline $\begin{array}{l}\text { Semáforo com tempo insuficiente } \\
\text { para realizar a travessia } \\
\text { Não } \\
\text { Sim }\end{array}$ & $\begin{array}{c}46(46,7)[\mathbf{- 0 , 4}] \\
8(7,3)[\mathbf{0 , 4}]\end{array}$ & $\begin{array}{c}43(42,3)[\mathbf{0 0 , 4}] \\
6(6,7)[-\mathbf{0 , 4}]\end{array}$ & 0,144 & 0,704 \\
\hline $\begin{array}{l}\text { Caminhos ruins, com iluminação } \\
\text { e/ou pavimentação deficientes } \\
\text { Não } \\
\text { Sim }\end{array}$ & $\begin{array}{r}19(18,9)[\mathbf{0 , 1}] \\
35(35,1)[-\mathbf{0 , 1}]\end{array}$ & $\begin{array}{l}17(17,1)[\mathbf{- 0 , 1}] \\
32(31,9)[\mathbf{0 , 1}]\end{array}$ & 0,003 & 0,958 \\
\hline $\begin{array}{l}\text { Poluição sonora ou poluição do ar } \\
\text { Não } \\
\text { Sim }\end{array}$ & $\begin{array}{c}37(32,5)[\mathbf{1 , 8}] \\
17(21,5)[-\mathbf{1}, \mathbf{8}]\end{array}$ & $\begin{array}{c}25(29,5)[\mathbf{- 1 , 8}] \\
24(19,5)[\mathbf{1}, \mathbf{8}]\end{array}$ & 3,283 & $0,070^{* *}$ \\
\hline $\begin{array}{l}\text { Medo de roubos, furtos ou } \\
\text { violência } \\
\text { Não } \\
\text { Sim }\end{array}$ & $\begin{array}{c}18(17,8)[\mathbf{0 , 1}] \\
36(36,2)[\mathbf{- 0 , 1}]\end{array}$ & $\begin{array}{l}16(16,2)[\mathbf{- 0 , 1}] \\
33(32,8)[\mathbf{0 , 1}]\end{array}$ & 0,005 & 0,942 \\
\hline $\begin{array}{l}\text { Trechos que exigem esforço físico } \\
\text { excessivo } \\
\text { Não } \\
\text { Sim }\end{array}$ & $\begin{array}{c}40(32,0)[\mathbf{3}, \mathbf{2}] \\
14(22,0)[-3,2]\end{array}$ & $\begin{array}{l}21(29,0)[-3,2] \\
28(20,0)[\mathbf{3}, \mathbf{2}]\end{array}$ & 10,366 & $0,001 *$ \\
\hline $\begin{array}{l}\text { Falta de cruzamentos acessíveis } \\
\text { Não } \\
\text { Sim }\end{array}$ & $\begin{array}{c}34(28,3)[\mathbf{2}, \mathbf{2}] \\
20(25,7)[-2,2]\end{array}$ & $\begin{array}{l}20(25,7)[-2,2] \\
29(23,3)[\mathbf{2 , 2}]\end{array}$ & 5,052 & $0,025^{*}$ \\
\hline $\begin{array}{l}\text { É difícil ver os carros ao } \\
\text { atravessar devido à presença de } \\
\text { obstáculos e à curvatura da rua } \\
\text { Não } \\
\text { Sim }\end{array}$ & $\begin{array}{c}39(36,2)[\mathbf{1 , 2}] \\
15(17,8)[-\mathbf{1}, \mathbf{2}]\end{array}$ & $\begin{array}{c}30(32,8)[-\mathbf{1}, \mathbf{2}] \\
19(16,2)[\mathbf{1}, \mathbf{2}]\end{array}$ & 1,405 & 0,236 \\
\hline $\begin{array}{l}\text { A rua é muito larga e não dá } \\
\text { tempo de atravessar } \\
\text { Não } \\
\text { Sim }\end{array}$ & $\begin{array}{c}51(47,7)[\mathbf{2 , 0}] \\
3(6,3)[-\mathbf{2}, \mathbf{0}]\end{array}$ & $\begin{array}{c}40(43,3)[-\mathbf{2 , 0}] \\
9(5,7)[\mathbf{2}, \mathbf{0}]\end{array}$ & 4,097 & $0,043^{*}$ \\
\hline
\end{tabular}

Nota: evidência de associação para nível de significância de $0,05^{*}$ e $0,10^{* *}$.

Adicionalmente, o estudo indica evidências de associação entre a dificuldade apontada como caminhos ruins, com iluminação elou pavimentação deficientes e a idade e a formação do indivíduo, o que mostra que a percepção sobre essa dificuldade tem relação com a faixa etária e o nível de estudo dos entrevistados. Os dados sugerem associação também entre as variáveis semáforo com tempo insuficiente para realizar a travessia e o estado de saúde do entrevistado, ou seja, a percepção sobre o tempo de travessia disponível para pedestres é influenciada pela condição de saúde do indivíduo. Além disso, existe associação entre a velocidade e o volume do tráfego como uma barreira ao movimento de pedestres com as dificuldades rua congestionada ou perigosa devido ao tráfego, poluição sonora ou do ar, trechos que exigem esforço físico excessivo, falta de cruzamentos acessíveis, a dificuldade de ver os carros ao atravessar devido à presença de obstáculos e ruas muito largas. Sendo assim, a percepção da população local com relação ao efeito barreira para os pedestres está associada à vivência em locais perigosos devido ao tráfego de veículos 
motorizados, ao nível de poluição, ao relevo e à largura das vias presentes na região de estudo, além da falta de locais com passagens acessíveis.

Uma considerável limitação para o estudo foi a quantidade de respostas obtidas, dado que a coleta foi interrompida antes do previsto devido à quarentena imposta pela pandemia associada ao vírus covid-19. Para trabalhos futuros sugerem-se a ampliação da coleta de dados, a análise de outras questões componentes do questionário e a realização de análises com o emprego de outros métodos, como árvores de decisão e florestas aleatórias, de forma a comparar e aprimorar os resultados.

\section{Referências}

AGRESTI, A. Contingency tables. In: AGRESTI, A. An introduction to categorical data analysis. $2^{\text {nd }}$. ed. Hoboken: Wiley-Interscience, 2007.

ANCIAES, P. R. What do we mean by "community severance"? Street Mobility and Network Accessibility Series, University College London, Londres, Working Paper n. 4, 2015. Disponível em:

https://discovery.ucl.ac.uk/id/eprint/1527807/1/Anciaes_ucl_streetmobility_paper04.pdf. Acesso em: 8 jun. 2020.

ANCIAES, P. R. et al. Urban transport and community severance: linking research and policy to link people and places. Journal of Transport and Health, v. 3, n. 3, p. 268-277, 2016.

ANCIAES, P. R.; JONES, P.; METCALFE, P. J. A stated preference model to value reductions in community severance caused by roads. Transport Policy, v. 64, p. 10-19, jan. 2018.

APPLEYARD, D.; LINTELL, M. The environmental quality of city streets: the residents' viewpoint. Journal of the American Planning Association, v. 38, n. 2, p. 84-101, 1972.

CANTILLO, V.; ARELLANA, J.; ROLONG, M. Modelling pedestrian crossing behaviour in urban roads: a latent variable approach. Transportation Research Part F: Traffic Psychology and Behaviour, v. 32, p. 56-67, 2015.

DEPARTAMENTO NACIONAL DE INFRAESTRUTURA DE TRANSPORTES. Manual de projeto geométrico de travessias urbanas. Departamento Nacional de Infraestrutura de Transportes - Instituto de Pesquisas Rodoviárias, 2010.

FUNDAÇÃO SISTEMA ESTADUAL DE ANÁLISE DE DADOS. Perfil dos municípios paulistas. 2020. Disponível em: https://perfil.seade.gov.br/. Acesso em: 10 jul. 2020.

G1. Faixas de pedestres apagadas podem causar acidentes em São Carlos, SP. 2015. Disponível em: http://g1.globo.com/sp/sao-carlos-regiao/noticia/2015/10/faixas-de-pedestres-apagadas-podem-causaracidentes-em-sao-carlos-sp.html. Acesso em: 8 jun. 2020.

GUO, X.; BLACK, J.; DUNNE, M. Crossing pedestrians and dynamic severance on urban main roads. Road and Transport Research, v. 10, n. 3, p. 84-98, 2001.

INSTITUTO BRASILEIRO DE GEOGRAFIA E ESTATÍSTICA. Cidades: censo demográfico de 2010. Disponível em: https://cidades.ibge.gov.br/brasil/sp/sao-carlos/panorama. Acesso em: 27 maio 2020.

LARA, D. V. R. Community severance and vertical equity assessment with spatially aggregated data. São Carlos, 2019. Dissertação (Mestrado em Planejamento e Operação de Sistemas de Transportes) - Escola de Engenharia de São Carlos, Universidade de São Paulo, São Carlos, 2019.

LARA, D. V. R.; RODRIGUES DA SILVA, A. N. Questões de equidade associadas a barreiras de transportes em uma cidade média. In: CONGRESSO DE PESQUISA E ENSINO EM TRANSPORTE DA ANPET, 32., Gramado, 2018. Anais [...] Rio de Janeiro, 2018.

LARA, D. V. R.; RODRIGUES DA SILVA, A. N. Equity issues associated with transport barriers in a Brazilian medium-sized city. Journal of Transport and Health, v. 14, p. 100582, jul. 2019.

MACKETT, R.; TITHERIDGE, H.; ACHUTHAN, K. Improving access in St Albans: report on a consultation exercise. Londres: University College London, 2010.

MINDELL, J. S. et al. Using triangulation to assess a suite of tools to measure community severance. Journal of Transport Geography, v. 60, p. 119-129, 2017.

MINISTÉRIO DAS CIDADES. Caderno de referência para elaboração de plano de mobilidade urbana. Brasília, 2015. 
MOUETTE, D.; AIDAR, T.; WAISMAN, J. Avaliação dos impactos do tráfego na mobilidade da população infantil. Revista Transportes, v. 8, p. 56-87, 2000.

MOUETTE, D.; WAISMAN, J. Proposta de uma metodologia de avaliação do efeito barreira. Revista dos Transportes Públicos - ANTP, v. 26, p. 33-54, segundo trimestre, 2004.

NIMEGEER, A. et al. Experiences of connectivity and severance in the wake of a new motorway: implications for health and well-being. Social Science and Medicine, v. 197, p. 78-86, 2018.

PREFEITURA MUNICIPAL DE SÃO CARLOS. Dados da Cidade. 2020. Disponível em: http://www.saocarlos.sp.gov.br/index.php/conheca-sao-carlos/115442-dados-da-cidade-geografico-edemografico.html. Acesso em: 8 jun. 2020.

SÃO CARLOS EM REDE. Miguel Petroni: um dos gargalos do trânsito para motoristas e perigo para pedestres em São Carlos. 2018. Disponível em: https://saocarlosemrede.com.br/miguel-petroni-um-dosgargalos-do-transito-para-motoristas-e-perigo-para-pedestres-em-sao-carlos/. Acesso em: 8 jun. 2020.

SECRETARIA DE SEGURANÇA PÚBLICA DE SÃO PAULO. Dados estatísticos de crimes e mortes do estado de São Paulo. 2017. Disponível em: https://www.ssp.sp.gov.br/Estatistica/Pesquisa.aspx. Acesso em: 10 jul. 2020.

\section{SECRETARIA MUNICIPAL DE HABITAÇÃO E DESENVOLVIMENTO URBANO. Banco de dados sobre volume do tráfego no município de São Carlos. São Carlos, 2002.}

SILVA JUNIOR, S. B.; FERREIRA, M. A. G. Rodovias em áreas urbanizadas e seus impactos na percepção dos pedestres. Sociedade \& Natureza, v. 20, n. 1, p. 221-237, 2008.

SOGUEL, N. C. Costing the traffic barrier effect: a contingent valuation survey. Environmental \& Resource Economics, v. 6, n. 3, p. 301-308, 1995.

THOREAU, R.; MACKETT, R. L. Transport, social exclusion and health. Journal of Transport and Health, v. 2, n. 4, p. 610-617, 2015.

VAN ELDIJK, J. et al. Missing links: quantifying barrier effects of transport infrastructure on local accessibility. Transportation Research Part D: Transport and Environment, v. 85, 2020.

VAN SCHALKWYK, M. C. I.; MINDELL, J. S. Current issues in the impacts of transport on health. British Medical Bulletin, v. 125, n. 1, p. 67-77, 2018.

YATES, F. Contingency tables involving small numbers and the $\chi^{2}$ test. Journal of the Royal Statistical Society, v. 1, n. 2, p. 217-235, supp. 1934.

Mylena Cristine Rodrigues de Jesus

Departamento de Engenharia de Transportes, Escola de Engenharia de São Carlos | Universidade de São Paulo | Av. Trabalhador Sãocarlense, 400, Centro | São Carlos - SP - Brasil | CEP 13566-590 | E-mail: mylenacrj@usp.br

Daniela Vanessa Rodriguez Lara

Departamento de Engenharia de Transportes, Escola de Engenharia de São Carlos | Universidade de São Paulo | Tel.: (16) 3373-9601 | E-mail: daniela.lara@usp.br

Antônio Nélson Rodrigues da Silva

Departamento de Engenharia de Transportes, Escola de Engenharia de São Carlos | Universidade de São Paulo | Tel.: (16) 3373-9595 | E-mail: anelson@sc.usp.br

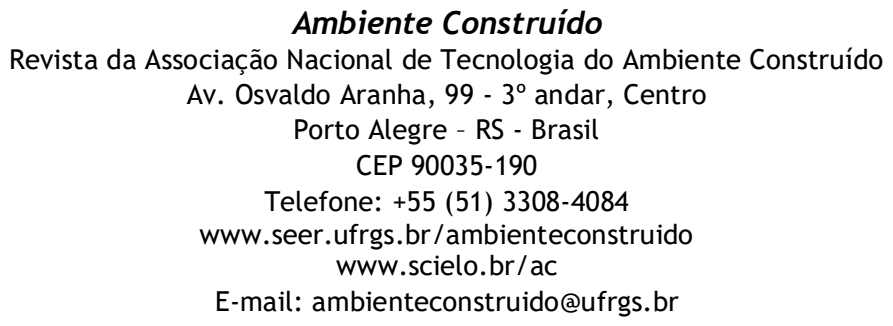

c) (i) This is an open-access article distributed under the terms of the Creative Commons Attribution License. 